\title{
Analysis of Tec Variations over Nepal Obtained from GPS Data on Geo-Magnetically Quiet and Disturbed Days of the Year 2015
}

\section{B. D. Ghimire, N. P. Chapagain, V. Basnet, B. Khadka}

Journal of Nepal Physical Society

Volume 7, Issue 2, June 2021

ISSN: 2392-473X (Print), 2738-9537 (Online)

Editors:

Dr. Binod Adhikari

Dr. Bhawani Joshi

Dr. Manoj Kumar Yadav

Dr. Krishna Rai

Dr. Rajendra Prasad Adhikari

Mr. Kiran Pudasainee

JNPS, 7 (2), 102-109 (2021)

DOI: https://doi.org/10.3126/jnphyssoc.v7i2.38630

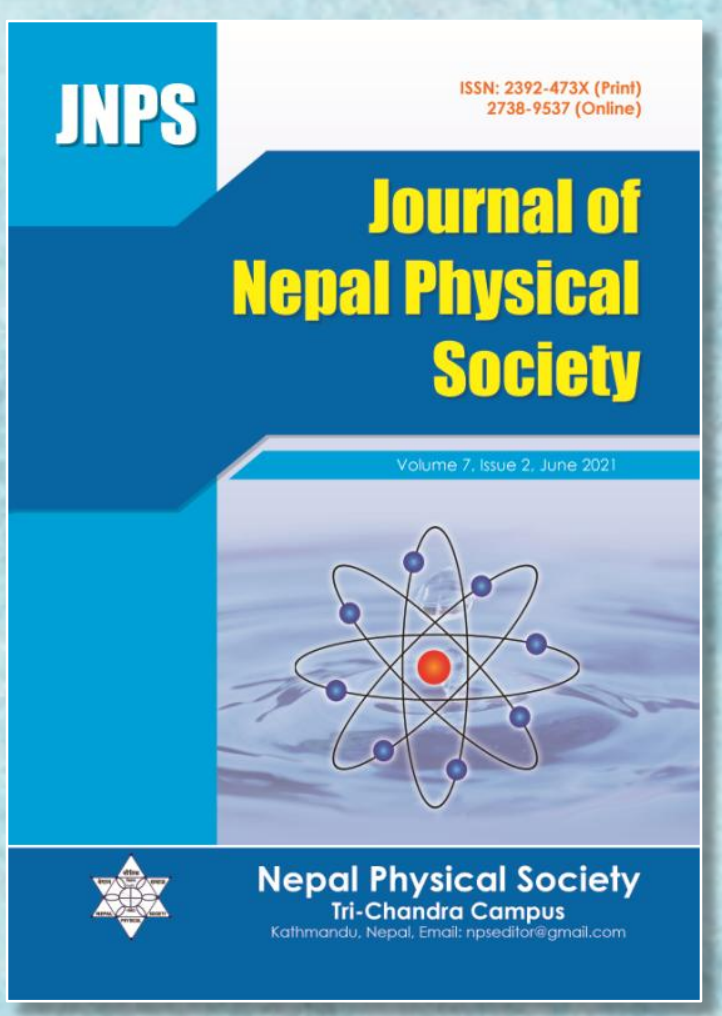

Published by:

Nepal Physical Society

P.O. Box: 2934

Tri-Chandra Campus

Kathmandu, Nepal

Email: nps.editor@gmail.com 


\title{
Analysis of Tec Variations over Nepal Obtained from GPS Data on Geo-Magnetically Quiet and Disturbed Days of the Year 2015
}

\author{
B. D. Ghimire ${ }^{1,3, *}$, N. P. Chapagain ${ }^{2}$, V. Basnet ${ }^{3}$, B. Khadka ${ }^{3}$ \\ ${ }^{1}$ Institute of Science and Technology, Central Department of Physics, Tribhuvan University, Kirtipur, Nepal \\ ${ }^{2}$ Amrit Campus, Tribhuvan University, Kathmandu, Nepal \\ ${ }^{3}$ St. Xavier College, Maitighar, Kathmandu \\ *Corresponding Email: basu.ghimire99@gmail.com
}

Received: 15 April, 2021; Revised: 28 May, 2021; Accepted: 20 June, 2021

\begin{abstract}
Dual frequency Global Positioning System (GPS) receiver in two nearby stations i.e. BESI $\left(28.228{ }^{\circ} \mathrm{N}, 84.739^{\circ} \mathrm{E}\right)$ and GHER $\left(28.375^{\circ} \mathrm{N}, 84.739^{\circ} \mathrm{E}\right)$ located at almost same latitude and longitude are used to measure ionospheric total electron content (TEC) for the year 2015. Since Year of 2014- 2016 have been known as most active years in terms of geomagnetic events, the year 2015 shows some abnormal results. Diurnal, monthly and seasonal variations of GPS TEC have been studied. The difference in the value of TEC is observed between quiet and disturbed days. Moreover, the correlation between GPS-data of each month with solar activities parameters such as Kp index, disturbance storm time (Dst) index, and Solar Flux index (F10.7 $\mathrm{cm}$ ) have been studied, separately for quiet and disturbed days for each station. In case of diurnal variation, mean TEC varies from $0100 \mathrm{UT}(\mathrm{LT}=\mathrm{UT}+5: 45)$ to maximum from $0900 \mathrm{UT}$ to 1100UT. The value of TEC is observed higher on quiet days than disturbed days. For seasonal variation, local seasons i.e. autumn, Spring, Summer and Winter is taken and, the value of TEC is found to be higher in Spring (March, April and May) in both stations in quiet and disturbed days. The difference in value of quiet and disturbed days of GPS-TEC explained the geomagnetic phenomena difference in these days in ionosphere. This study can be useful to calculate the water vapor concentration in the atmosphere which is useful for weather prediction and meteorological department.
\end{abstract}

Keywords: GPS, TEC, Solar Indices, Quiet and Disturbed.

\section{INTRODUCTION}

Ionosphere is the region extending from $60 \mathrm{~km}-$ $1000 \mathrm{~km}$ differentiated into different layers. Ionosphere contains different types of ions and electrons so its changing behavior is very interesting and mysterious. Different types of researches and studies are going in the basis of TEC. It is one of the significant parameters to study the ionospheric dynamics on the basic of variation of TEC with local time, seasons and solar activities [-4]. In past years, GPS has become an important tool to study ionospheric character [5 67 8]. Due to increment in demand of GPS- based navigation appliances in satellites, aircrafts and other transportations, the study of TEC is heightened [9]. The GPS-TEC is the total number of electrons in a vertical column of $1 \mathrm{~m}^{2}$ cross-section from the height of the GPS satellite $(\sim 20,000 \mathrm{~km})$ to the receiver on the ground. It is measured in TEC Unit (TECU) and 1 TECU is equal to $1 \times 10^{16} \mathrm{el}$ $m^{-2}[10]$. The ionospheric delay which is proportional to TEC is the highest contributor of GPS positional errors[10]. TEC helps us to understand the changes of ionosphere that may be either long -term or short-term caused by the factors like solar activities, geomagnetic storms and meteorological influences [1, 4, 11]. Many ionospheric studies are done for disturbed and quiet days $[4,6,8,11,12]$. Besides that, Global maps of ionospheric TEC have been made for the measurements of Vertical TEC (VTEC) and also used to calibrate the delay of radio signals[13]. 


\section{MATERIALS AND METHODS}

GPS data obtained from satellite and receiver needs to process. Chauhan et al. (2011) and Arikan et al. (2003) [7, 14 ] have given different methods for calculation of TEC. In this paper, the method given by Chauhan et al. (2011) is followed. Using a dual frequency receiver having $\mathrm{L} 1=1575.42 \mathrm{MHz}$ and $\mathrm{L} 2=1227 \quad \mathrm{TEC}$ measurements have been carried out through combined frequencies such as

$$
\mathrm{TEC}=\left[9.483^{*}\left(\mathrm{PR}_{\mathrm{L} 2}-\mathrm{PR}_{\mathrm{L} 1}-\Delta_{\mathrm{C} / \mathrm{A}-\mathrm{P}, \mathrm{PRN}}\right)+\mathrm{TEC}_{\mathrm{RX}}+\mathrm{TEC}_{\mathrm{CAL}}\right] \mathrm{TECU} \ldots \text { (1) [8] }
$$

Where, $\mathrm{PR}_{\mathrm{L} 1}$ and $\mathrm{PR}_{\mathrm{L} 2}$, are pseudo-range in meters for $\mathrm{L}_{1} \quad(1227.45 \mathrm{MHz})$ and $\mathrm{L}_{2} \quad(1555.60 \mathrm{MHz})$ frequencies respectively; $\Delta_{\mathrm{C} / \mathrm{A}-\mathrm{P}}$, PRN, is the input bias between satellite $\mathrm{C} / \mathrm{A}-$ and P-code chip transition in meters [15]. There are 32 pseudo random noise (PRN) values (one for each satellite) which added to the C/A code pseudo-range measurements. $\mathrm{TEC}_{\mathrm{RX}}$ is the TEC result due to internal receiver $\mathrm{L}_{1} / \mathrm{L}_{2}$ delay and $\mathrm{TEC}_{\mathrm{CAL}}$ is the calibration error for user [15]. As shown in Figure 1, Slant TEC (STEC) depends upon ray path geometry through the ionosphere, an independent and equivalent VTEC of elevation angle is calculated [5] using a mapping function as shown in equation 2, and geometry of Figure 1.

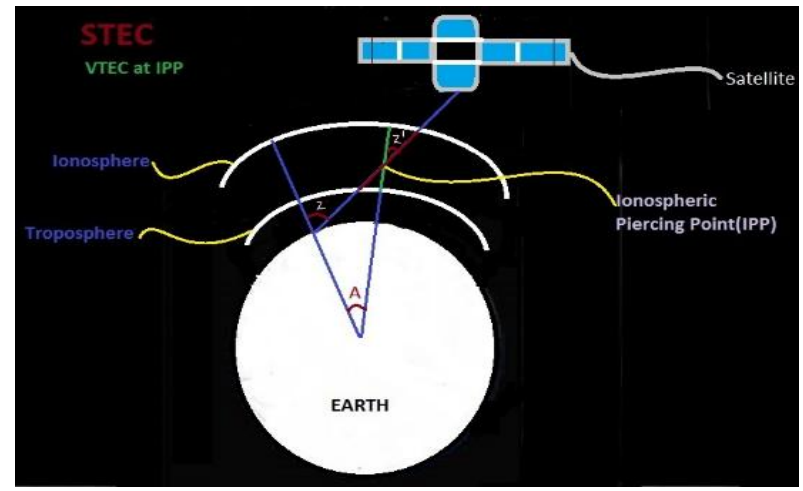

Fig.1: Conversion of STEC to VTEC source

$$
S(E)=\frac{1}{\cos (Z)}=\left\{1-\left(R_{E} * \frac{\cos (E)}{R_{E}+h_{S}}\right) \wedge 2\right\} \wedge-0.5
$$

where, $R_{E}$, is the mean radius of the earth in; $h_{S}$, the ionosphere (effective) height above the earth's surface; Z, the zenith angle; and E, the elevation angle in degrees [7]. Rama Rao et al. (2006) [9] observed that the IPP (Ionospheric Pierce Point) attitude of $350 \mathrm{~km}$ is valid for the satellite elevation angle greater than $20^{\circ}$. A GPS receiver can lock the signal of more than one satellite at a time at different angle of elevation from the receivers. Due to different ray path, STEC as measured at a time on the receiver differs from one satellite to another. Hence we have separated the values of STEC for each satellite with their unique PRN code.

The codes help in identification of the satellite by a receiver, while receiving its data. PRN are used as an identification measure in code division multiple access (CDMA) based satellite navigation system [16]. Each Satellite throughout the world within a GNSS constellation has a unique PRN code that it transmits as part of the Civilian Access navigation message, which allows receiver to identify exactly which satellite(s) it is receiving [17].

There are various GPS stations (as shown in Figure 2) which are installed in Nepal among those stations we analyzed two stations data TEC data is obtained from GPS which is made available by UNAVCO in the form of RINEX (Receiver Independent Exchange Format) www.unavco.org . The RINEX files are processed into American slandered code for information interchange (ASCII) files by using Gopi Semeela Software [18] https://seemala.blogspot.com. Two stations BESI $\left(28.228{ }^{0} \mathrm{~N}, 84.739^{0} \mathrm{E}\right)$ and GHER $\left(28.375{ }^{0} \mathrm{~N}\right.$, $84.739^{\circ} \mathrm{E}$ ) are taken for this study.

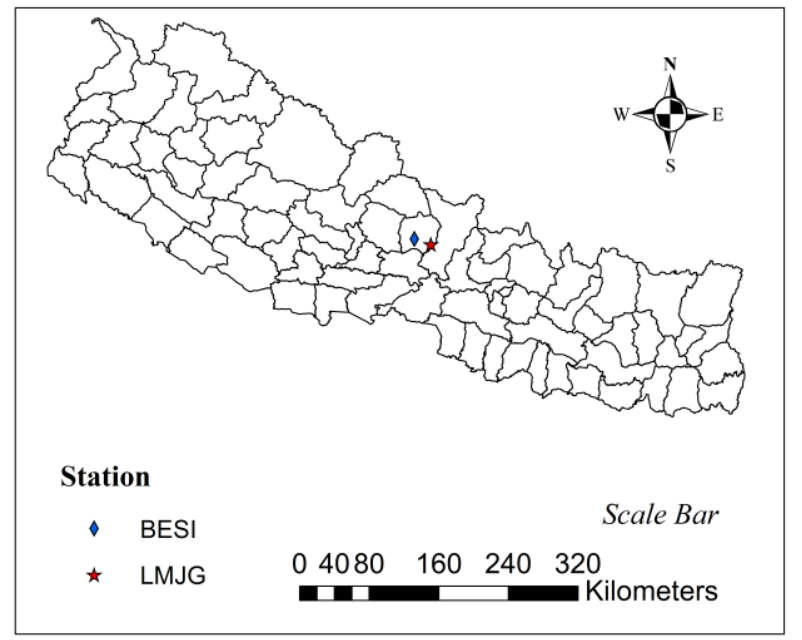

Fig. 2: Map of Nepal showing GPS stations.

Data of every $60 \mathrm{sec}$ was obtained from these stations and then was processed into hourly data. 
The mean TEC value is taken in our study. These stations are nearly at same latitude and longitude. Five quietest and ten most disturbed days of the month was obtained from two authorized site http://isgi.unistra.fr/events_qdays.php and http://wdc.kugi.kyoto-u.ac.jp/qddays/index.html

\section{RESULTS AND DISCUSSIONS}

Diurnal, Seasonal and Monthly variations of GPSTEC from two stations BESI and GHER have been studied on Geo-magnetically quiet and disturbed days. Separate study has been performed for better understanding of each case.

Data of all months were not available for every month due to the technical problems at the stations. Data of February to October was available of BESI station with few missing days. Data of February to
December was available of GHER station with few missing days.

\subsection{Diurnal Variation of TEC}

Diurnal variation of TEC has been studied separately for quiet and disturbed days for two stations of the year 2015. Graphs of each quiet and disturbed day are presented for each month showing daily change. The value of TEC was greater for quiet days than disturbed days in some months and days which are opposite to the general result i.e. the higher value of VTEC in Disturbed days than Quiet days. It suggested that a TEC value does not only depend upon solar parameters.

\subsubsection{Quiet Days Variation}

Figure (3) and figure (4) show the mass data plots of quiet days obtained from two stations i.e. BESI and GHER respectively of the year 2015.
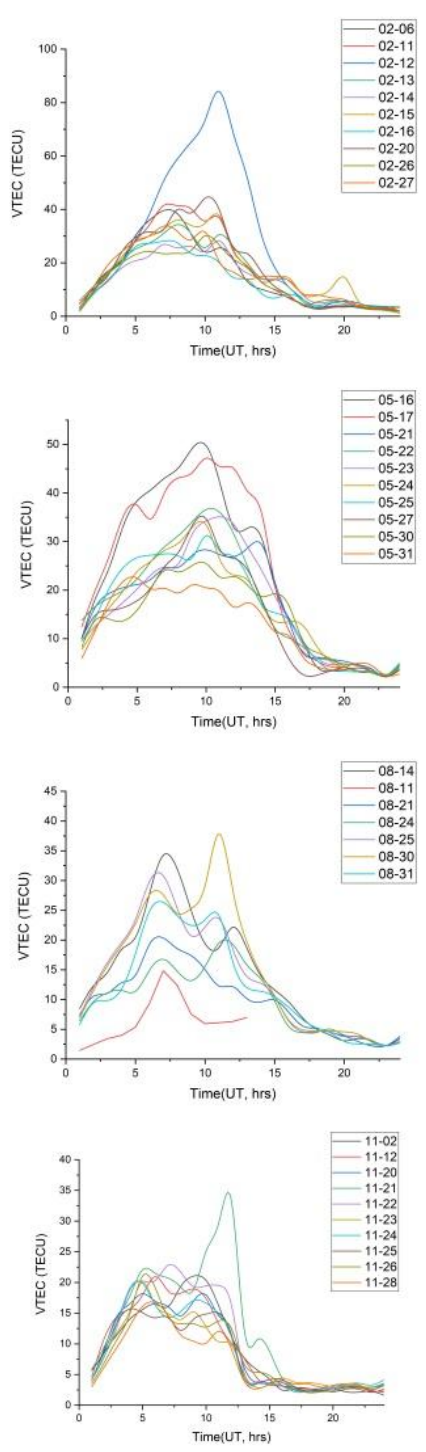
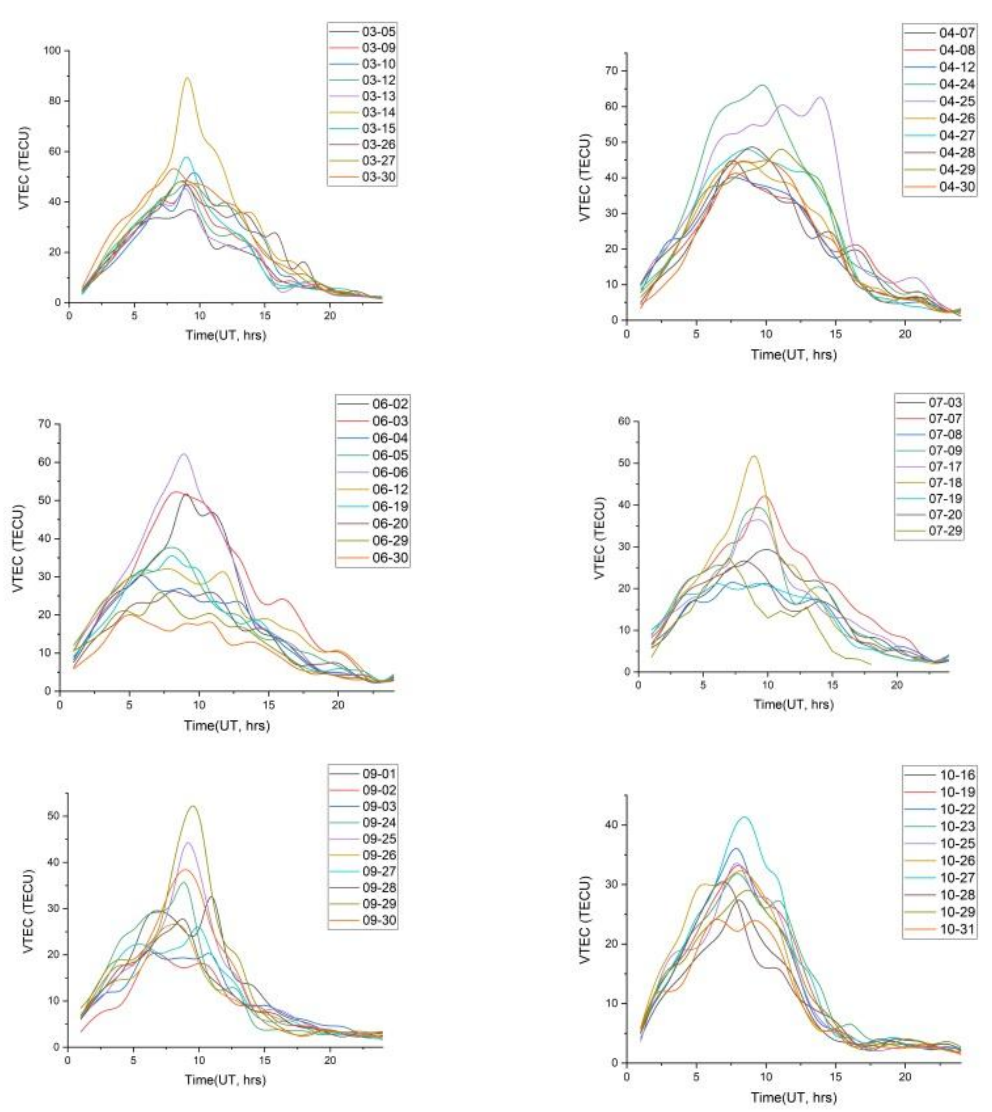

Fig. 3: Mass plots of quite days of month 2015 for the BESI station 

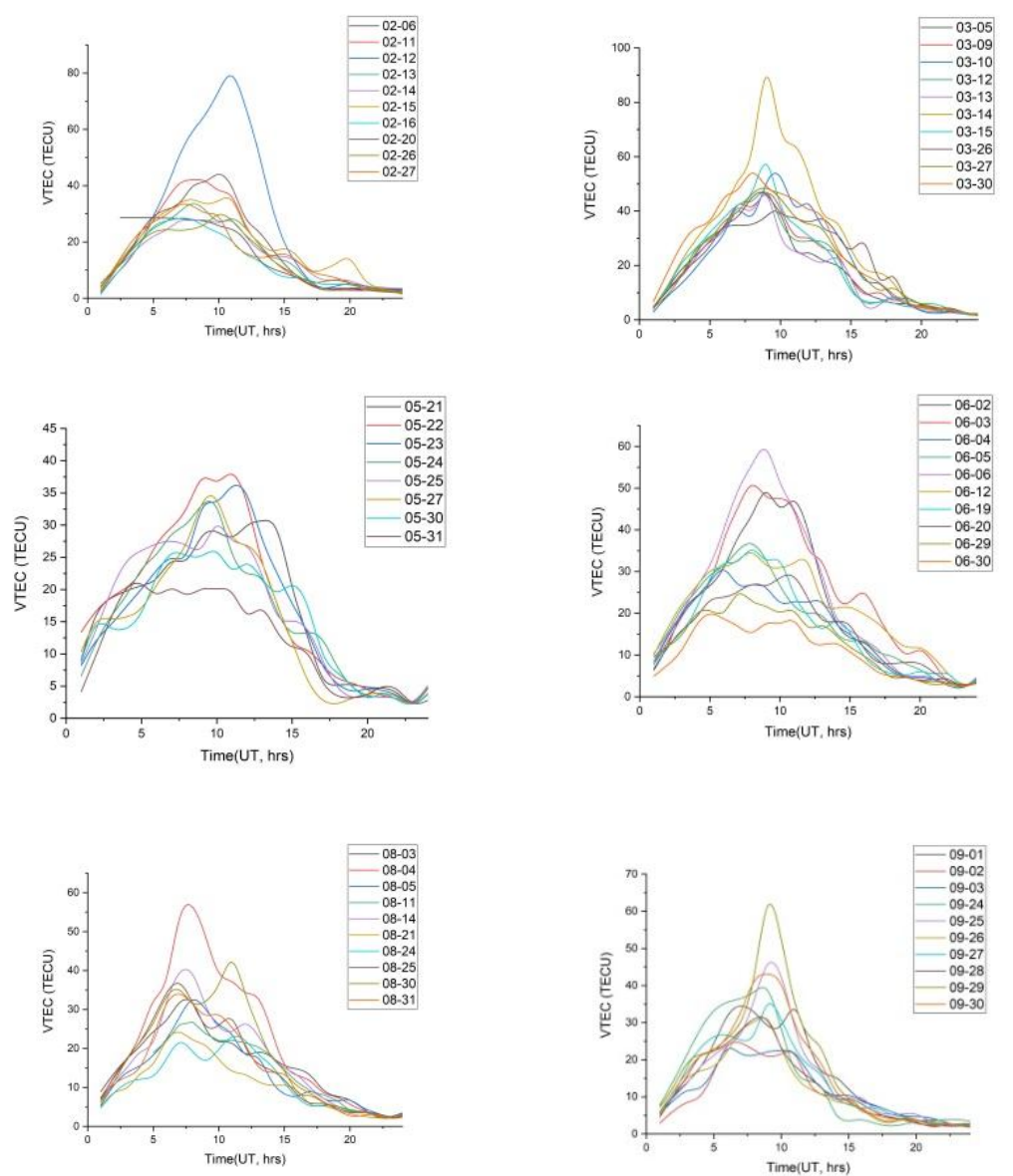
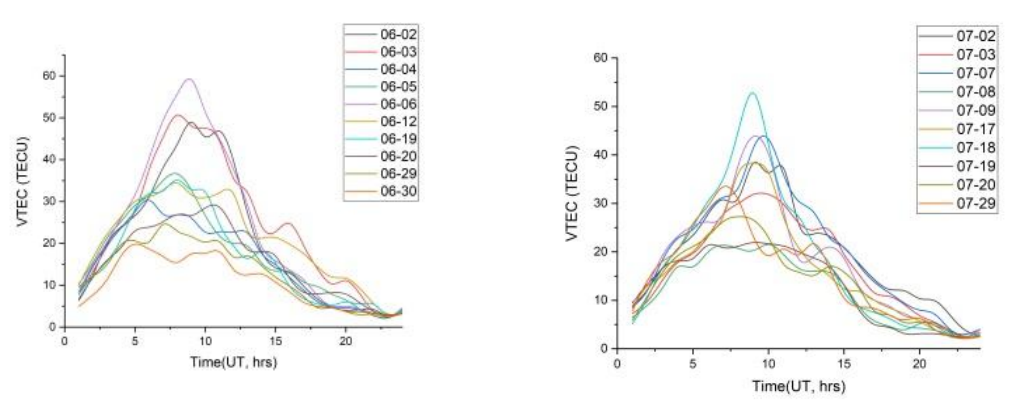

Fig. 4: Mass plots of quite days of month 2015 for the GHER station

From the graph, it can be observed that the maximum value occurs from 0900UT to $1100 \mathrm{UT}$. Generally, the diurnal variation of TEC is minimum a pre-dawn, a steady increase in the early morning followed by afternoon maximum then gradual decrease after the sunset. The variation for peak value of TEC differs each and every day and also the time of the peak value. The peak value of VTEC in BESI station has been found from 0800UT to 1100UT. The highest value of VTEC has been observed to be 89.39 TECU in March and the lowest to be 37.88 TECU in May. The peak value of VTEC in GHER station has been found from 0800UT to $1200 \mathrm{UT}$. The highest value of VTEC has been found to be 89.27 TECU in March and the lowest to be 33.29 TECU in November. Variation for daytime was larger than night time for every station. The higher value of TEC is found in February, March and April compared to other months. The enhancement of TEC particularly at the low latitude stations during daytime can be associated with the upward drift of plasma caused by the fountain effect as a result of $\mathrm{E} \times \mathrm{B}$ drift and the consequent gravity force and gradient pressure which form two peaks known as the EIA [19].

\subsubsection{Disturbed day's variation}

Figure (5) and figure (6) show the mass data plots of disturbed days of the stations taken in our study i.e. BESI and GHER respectively. Similar type of graph was obtained as in quiet days but the values were low as compared to quiet days. Large variation was observed in daytime than night time as in quiet days. The time and value was varied each and every day. The highest value of TEC was mainly observed from 0800 UT to 1100UT. The first super geomagnetic storm (Dst<-200 nT) of solar cycle 24 occurred on "St. Patrick's day" on $17^{\text {th }}$ March [12]. The peak value of VTEC in BESI has been found from 0700 UT to 1300 UT. The highest value of VTEC has been found to be 69.817 TECU in April and the lowest to be 35.14 TECU in August. The peak value of VTEC In GHER has been observed from 0700 UT to 1300 UT .The highest value of VTEC has been found to be 66.35 TECU in April and the lowest to be 30.60 TECU in September. 

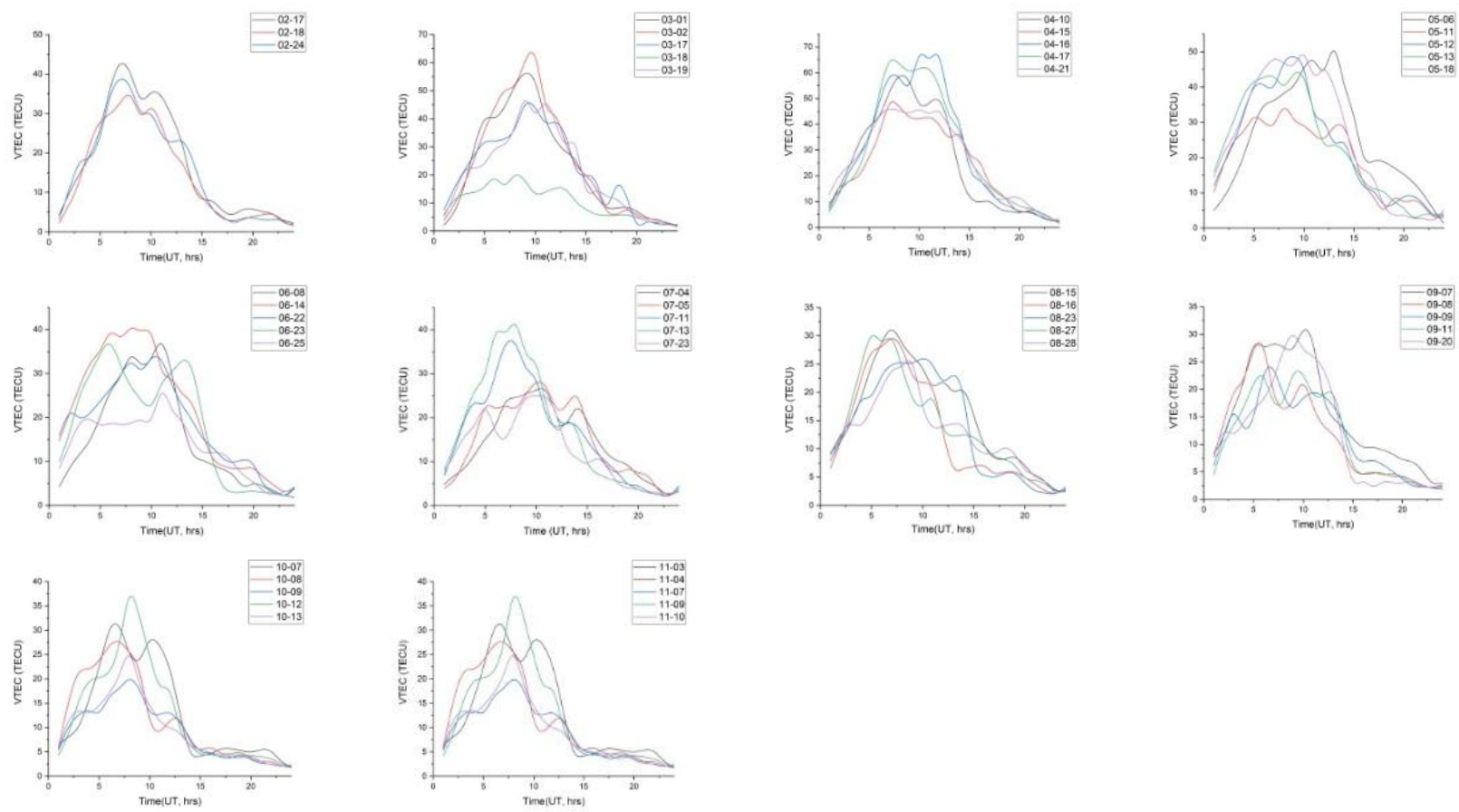

Fig. 5: Diurnal variation of VTEC (TECU) of disturbed days of BESI station of the year 2015
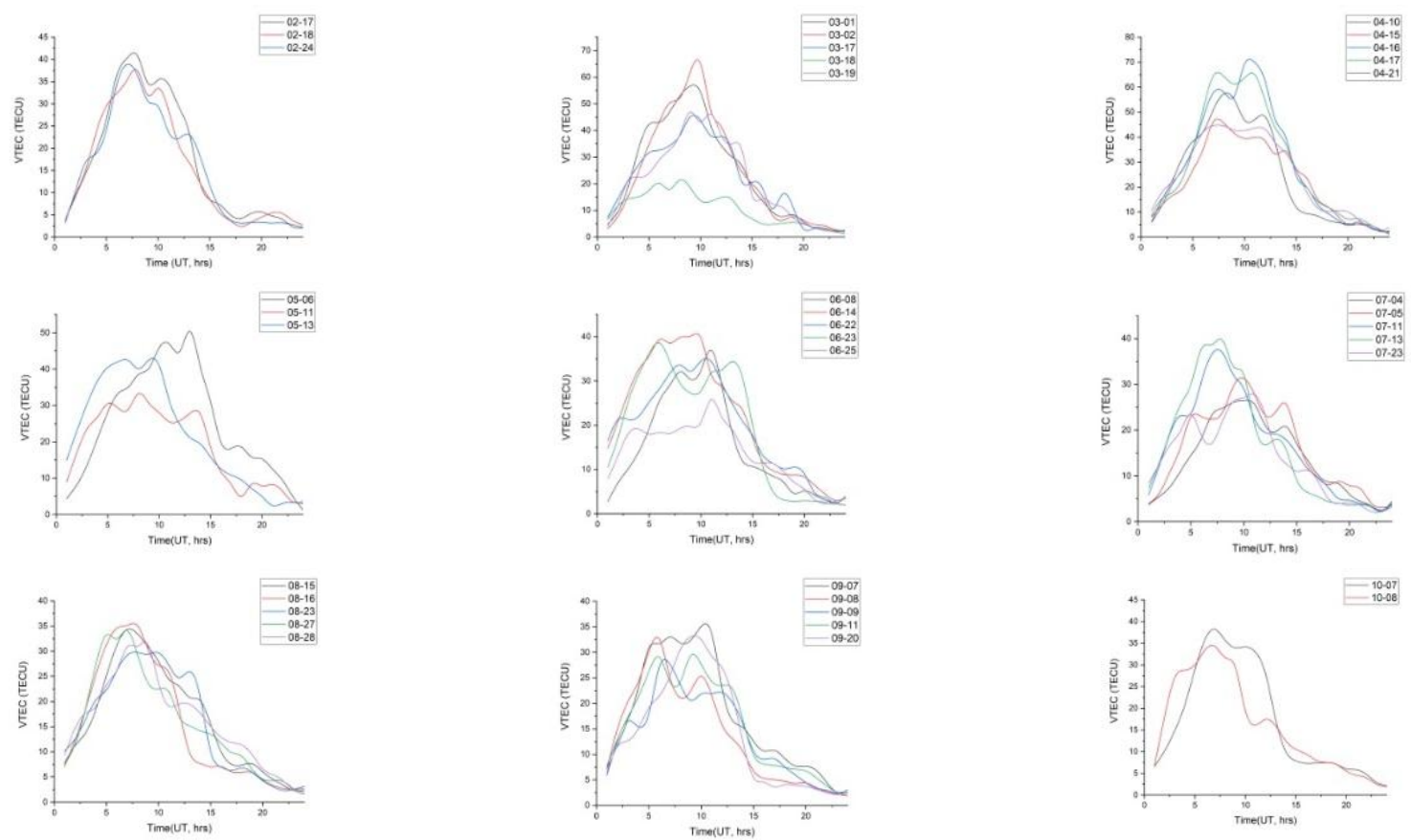

Fig. 6: Diurnal variation of VTEC (TECU) of disturbed day of GHER station of the year 2015.

\subsection{Seasonal Variation of TEC}

Seasonal variation of the year 2015 for two stations has been observed. Local seasons, autumn (September, October and November), spring (March, April and May), summer (June, July and August) and winter (December, January and February) were taken for the study with consisting each of 3 months. TEC value of spring was found to be greater than other seasons. Hourly data was compared to seasons. The peak value of VTEC has been found from 0800LT to 1000 UT for different seasons. Analysis for quiet and disturbed days was done separately for each seasons and stations.

\subsubsection{Quiet Days}

Figure (7) show the graph of the seasonal variations for the stations i.e. BESI and GHER, respectively 
taken in our study for quiet days. The value and time for peak value varies every season.
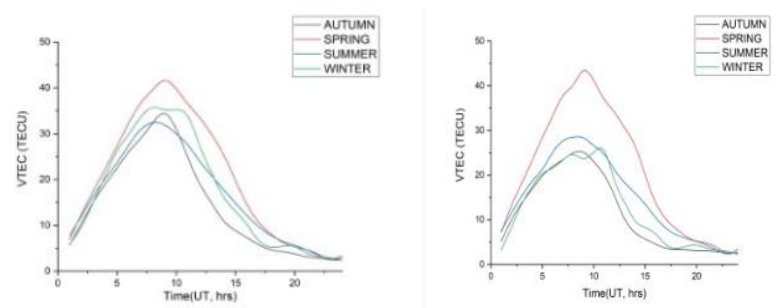

Fig. 7: Seasonal variation of VTEC (TECU) of quiet day of GHER and BESI stations of the year 2015

The peak value of VTEC in BESI has been observed around 0800 UT to 0900 UT. The highest value of VTEC has been found to be 42.58 TECU in spring at 0900 UT than other months whereas the lowest value has been found to be 32.78 TECU in summer at 0800 UT. The peak value of VTEC in GHER has been found around 0800 UT to 1100 UT. The highest value of VTEC has been found to be 43.38 TECU in spring at 0900 UT and the lowest has been found to be 25.12 TECU in Autumn at 0900 UT.

\subsubsection{Disturbed Days}

Figure (8) show the seasonal variations for disturbed days for stations BESI (left) and GHER (right) respectively. Similar observations were obtained for disturbed days as in quiet days. The peak value of VTEC in BESI has been found from 0800 UT to $1000 \mathrm{UT}$. The highest value of VTEC has been found to be $44.87 \mathrm{TECU}$ in spring at 0900 UT and the lowest has been found to be 28.48 TECU in autumn at 100UT. The peak value of VTEC in GHER has been found from 0800LT to 0900LT. The highest value of VTEC has been found to be 43.38 TECU in Spring at 0900 UT and the lowest has been found to be 24.84 TECU in Autumn at 0800 UT.
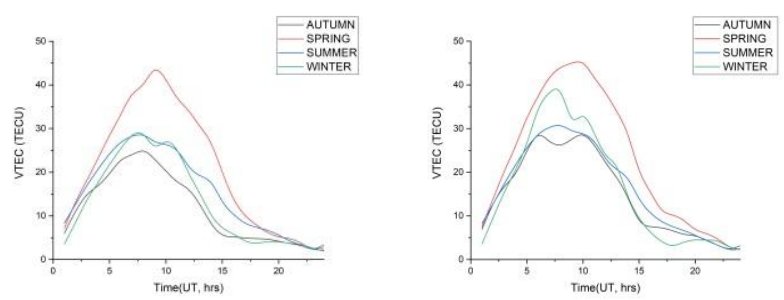

Fig. 8: seasonal variation of the year 2015 for disturbed days for stations BESI and GHER

\subsection{Monthly Variation of TEC}

Mean TEC of each month has been taken and the values were plotted for both stations i.e. BESI and
GHER. Separate analysis has been performed for quiet and disturbed day.

\subsubsection{Quiet Days}

Figure (9) show the monthly variation of the year 2015 for quiet days for stations BESI and GHER respectively. In BESI, the highest value of VTEC has been found to be 29.09 TECU in April and the lowest was found to be 15.36 TCU in August. In GHER, the highest value of VTEC has been found to be 23.12 TECU in April and the lowest value has been found to be 7.77 TECU in December in GHER.
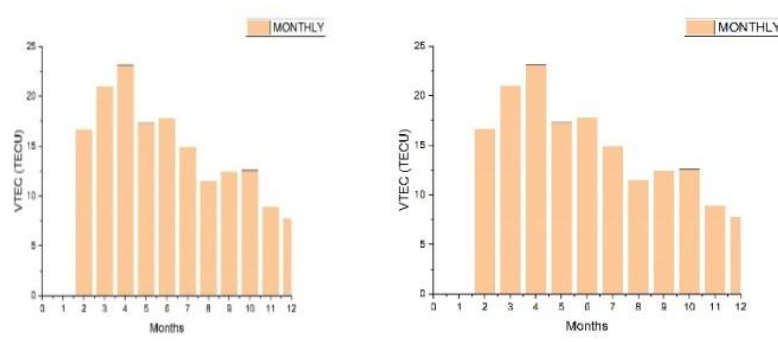

Fig. 9: Monthly variation of the year 2015 for quite days for stations BESI and GHER respectively

\subsubsection{Disturbed Days}

Figure (10) show the monthly variation of VTEC in two stations BESI and GHER, respectively. In BESI, the highest value of VTEC has been found to be 26.12 TECU in April and the lowest value has been found to be 14.76 TECU in September. In GHER, the highest value of VTEC has been found to be 23.00 TECU in May and the lowest value has been found to be 8.58 TECU in April.
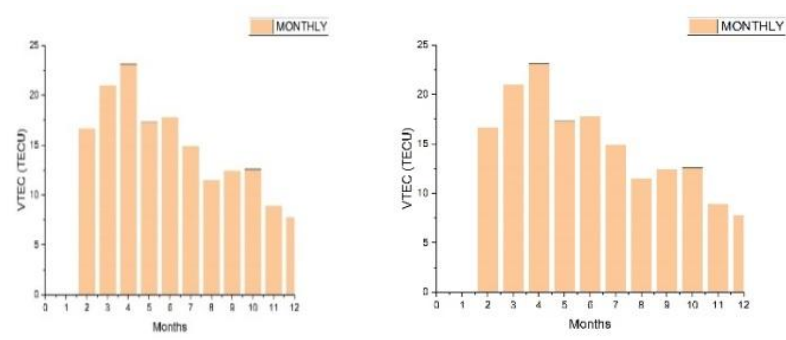

Fig. 10: monthly variation of the year 2015 for quite days for stations BESI and GHER respectively

\section{CONCLUSION}

Diurnal, Seasonal and Monthly variations of GPSTEC have been studied for both stations i.e. BESI and GHER stations for the year 2015 which are located at almost same latitude and longitude. The study for it was done separately for quiet and disturbed days. Mean TEC varies from 0100 UT $(\mathrm{LT}=\mathrm{UT}+5: 45)$ to maximum from $0900 \mathrm{UT}$ to 
1100 UT showing pre- dawn minimum and steep rise in the morning and peak value around $1100 \mathrm{U}$ and then gradual decrease after sunset. The highest value of TEC was observed in spring for both stations. The difference in value of quiet and disturbed days of GPS- TEC explained the geomagnetic phenomena difference in these days in ionosphere. This study may be useful to calculate the water vapor concentration in the atmosphere which is useful for weather prediction and meteorological department which is also described in my previous paper [8 9].

\section{ACKNOWLEDGEMENT}

This research is carried out on the under the fellowship of University Grants Commission (UGC), so we would like to thank for University Grants commission (PhD-74/75-S\&amp;T-13).We also thanks NASA's OmniWeb data explorer for quiet and disturbed days. Finally, we would also like to thank UNAVCO for providing the data of all stations and days.

\section{REFERENCES}

[1] Forbes, J. M.; Palo S. E.; Zhang X. Variability of the ionosphere, J. Atmos. Sol. Terr. Phys., 62: 685-693 (2000).

[2] Rishbeth, H. and mendillo M. Patterns of F2 layer variability, J. Atmos. Sol. Terr. Phys., 63: 16611680 (2001).

[3] Kane, R. P. Day-to-day variability of quiet-time ionospheric foF2. India Journal of Radio \& Space Physics, 32: 344-348 (2003).

[4] Tsurutani, B. T.; Verkhoglyadova, O. P.; Mannucci, A. J.; Saito, A.; Araki, T.; Yumoto, K.; ... \& Vasyliūnas, V. M. Prompt penetration electric fields (PPEFs) and their ionospheric effects during the great magnetic storm of 30-31 October 2003. Journal of Geophysical Research: Space Physics, 113: A5 (2008).

[5] Bagiya, M. S.; Joshi, H. P.; Iyer, K. N.; Aggarwal, M.; Ravindran, S. \& Pathan, B. M. "TEC variations during low solar activity period (2005-2007) near the equatorial ionospheric anomaly crest region in India" In Annales Geophysicae, 27: 1047-1057 (2009).

[6] De Siqueira, P. M.; De Paula, E. R.; Muella, M. T. A. H.; Rezende, L. F. C.; Abdu, M. A. \& Gonzalez, W. D. Storm-time total electron content and its response to penetration electric fields over South America. In Annales Geophysicae, 29: 1765-1778 (2011).

[7] Chauhan, V.; Singh, O. P. \& Singh, B. "Diurnal and seasonal variation of PS-TEC during a low sssolar activity period as observed at a low latitude station Agra" Indian Journal of Radio and Space Physics, 40(1): 26-36 (2011).

[8] Ghimire, B. D.; Chapagain, N. P.; Basnet, V.; Bhatta, K. \& Khadka, B. "Variation of Total Electron Content (TEC) in the Quiet and Disturbed days and their correlation with Geomagnetic Parameters of Lamjung Station in the year of 2015". BIBECHANA, 17: 123-132 (2020).

[9] Ghimire, B. D.; Chapagain, N. P.; Basnet, V.; Bhatta, K. \& Khadka, B. "Variation of GPS-Tec Measurements of the Year 2014: A Comparative Study with IRI-2016 Model". Journal of Nepal Physical Society, 6(1): 90-96 (2020).

[10] Rama Rao, P. V. S.; Niranjan, K.; Prasad, D. S. V. V. D.; Gopi Krishna, S. \& Uma, G. "On the validity of the ionospheric pierce point (IPP) altitude of $350 \mathrm{~km}$ in the Indian equatorial and low-latitude sector" Annales Geophysicae, 24(8): 2159-2168(2006).

[11] Chauhan, V.; Singh, O. P. \& Singh, B. "Diurnal and seasonal variation of GPS-TEC during a low sssolar activity period as observed at a low latitude station Agra." Indian Journal of Radio and Space Physics, 40(1): 26-36 (2011).

[12] Jonah, O. F. Analysis of total Electron Content (TEC) Variation Obtained from GPS data over south America Dissertation Master at Graduation Course in Space Geophysics, ad- vised by Drs . Eurico Rodrigues de Severino Luiz Guimaraes Dutra (2013).

[13] De Paula, E. R.; De Rezende, L. F. C.; Kantor, I. J.; Campos, A. A. N.; Smorigo, P. F. Ionospheric irregularities studies using GPS. Simpósio Brasileiro de Geofísica Espacial E Aeronomia, 2006, São José dos Campos. Livro de Resumos... São José dos Campos: SBGF, 29 (2006).

[14] Arikan, F.; Erol, C. B. \& Arikan, O. Regularized estimation of vertical total electron content from Global Positioning System data. Journal of Geophysical Research: Space Physics, 108(A12): 1-12 (2003).

[15] Mannucci, A. J.; Wilson, B. D.; Yuan, D. N.; Ho, C. H.; Lindqwister, U. J. \& Runge, T. F. A global mapping technique for GPS-derived ionospheric total electron content measurements. Radio Science, 33(3): 565-582(1998).

[16] Marques, H. A. S.; Monico, J. F. G. \& Marques, H. A. Performance of the L2C civil GPS signal under various ionospheric scintillation effects. GPS solutions, 20(2): 139-149 (2016).

[17] Abdu, M. A.; Brum, C. G. M.; Batista, I. S.; Sobral, J. H. A.; De Paula, E. R. and Souza, J. R. "Solar flux effects on equatorial ionization anomaly and total electron content over Brazil: 
observational results versus IRI representations". Advances in space research, 42: 617-625.

[18] Seemala, G. K. \& Valladares, C. E. Statistics of total electron content depletions observed over the southern American continent for the year 2008. Radio Science, 46 -RS5019 (2011).

[19] Gupta, J. K. and Singh, L. Long term ionospheric electron content variations over Delhi, Ann. Geophys., 18: 1635-1644 (2000). 